
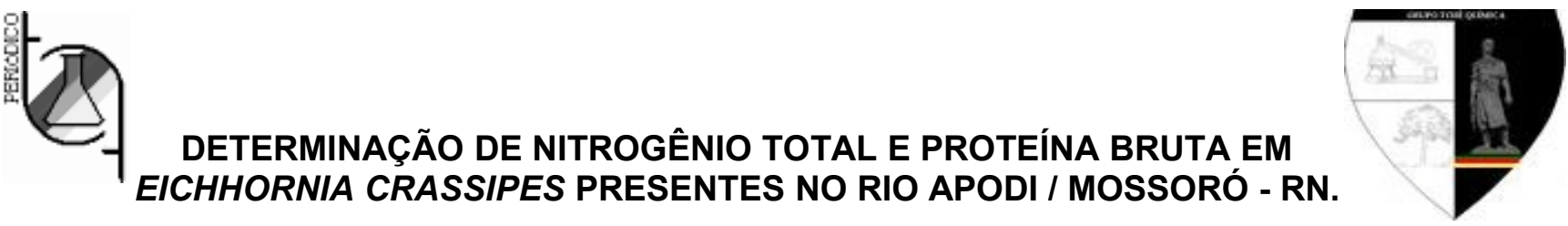

\title{
DETERMINATION OF TOTAL NITROGEN AND CRUDE PROTEIN IN EICHHORNIA CRASSIPES PRESENTS IN RIVER APODI / MOSSORÓ - RN.
}

\author{
MARTINS, Daniel Freitas Freire ${ }^{1}$; MOURA, Maria de Fátima Vitória²; SOUZA, Luiz Di³ ${ }^{3}$ CAMACHO, \\ Ramiro Gustavo Valera*; SILVA, Alriberto Germano ${ }^{5}$; ROCHA, Lamarck do Nascimento Galdino ${ }^{6}$. \\ 1,2 Universidade Federal do Rio Grande do Norte - UFRN, Campus Universitário Lagoa Nova, CEP 59072-970 - \\ Caixa Postal - 1524, Natal - RN - Brasil \\ * e-mail: dffmquimica@hotmail.com
}

3, 4, 5,6 Universidade do Estado do Rio Grande do Norte - UERN, BR 110 - Km 46 - Rua Prof. Antônio Campos, s/n - Bairro Costa e Silva, CEP: 59.633.010 - Caixa Postal 70 - Mossoró - RN - Brasil.

\section{RESUMO}

As macrófitas aquáticas absorvem do meio grande quantidade de nutrientes essenciais ou não ao seu desenvolvimento. O objetivo deste trabalho foi determinar a quantidade de nitrogênio total [EMBRAPA, 1999] e o teor de proteína bruta [Boyd, 1970] presente em macrófitas aquáticas da espécie Eichhornia crassipes, relacionando os valores obtidos com a variabilidade temporal. A partir dos resultados de área foliar $(23,17$; 67,$21 ; 88,59$ e $\left.100,29 \mathrm{~cm}^{2}\right)$, nitrogênio total $(4,4088 ; 3,1649 ; 2,1241$ e $1,5256 \mathrm{~g} / 100 \mathrm{~g}$ ) e proteína bruta $(27,5549 ; 19,7805 ; 13,2755$ e $9,5351 \mathrm{~g} / 100 \mathrm{~g})$, pode-se concluir que os níveis de nitrogênio total e proteína bruta diminuem ou mantêm-se constantes com o crescimento da planta. Desta forma, as plantas menores são as que apresentam maiores concentrações destes nutrientes.

Palavras-chave: Absorção de nutrientes; Plantas aquáticas; Variabilidade temporal.

\begin{abstract}
The aquatic macrophytes absorbs from the environment a large amount of nutrients, whether essential or not to its development. The objective of this study was to determine the amount of total nitrogen [EMBRAPA, 1999] and crude protein [Boyd, 1970] present in aquatic macrophytes of species Eichhornia crassipes linking the values obtained with the temporal variability. According to the results of leaf area $(23.17 ; 67.21 ; 88.59 \mathrm{e}$ $\left.100.29 \mathrm{~cm}^{2}\right)$, total nitrogen $(4.4088 ; 3.1649 ; 2.1241 \mathrm{e} 1.5256 \mathrm{~g} / 100 \mathrm{~g})$ and crude protein $(27.5549 ; 19.7805$; 13.2755 e $9.5351 \mathrm{~g} / 100 \mathrm{~g}$ ), can be concluded that the total nitrogen levels and crude protein decrease or remain constant with the growing of the plant. Thus, the smaller plants have higher concentrations of these nutrients.
\end{abstract}

Keywords: Absorption of nutrients; Aquatic plant; Temporal variability. 


\section{Introdução}

Água limpa e de boa qualidade é um produto precioso, em especial, no semi-árido brasileiro onde este recurso é escasso. No estado do Rio Grande do Norte, a Bacia Hidrográfica do Rio Apodi/Mossoró tem um curso de $210 \mathrm{~km}$ de extensão, ocupa aproximadamente $14.276 \mathrm{~km}^{2}$ ( $26,8 \%$ do Estado), possui vazão de cerca de 360 milhões de $\mathrm{m}^{3} / \mathrm{ano}$, e destaca-se como o mais importante recurso hídrico superficial de toda a região oeste-potiguar [Martins et al., 2008a].

Este rio desempenha papel chave no desenvolvimento econômico da região, fato que pode ser constatado pelas atividades agrícolas em suas margens, pelas micro-empresas ribeirinhas, pela pesca e outras atividades econômicas, sendo todas elas comuns em locais onde há o descarte de efluentes sem tratamento adequado [Martins et al., 2008b].

Há algum tempo vem se tentando desenvolver métodos mais eficazes de despoluição de ambientes aquáticos. As macrófitas aquáticas, por necessitarem de altas concentrações de nutrientes para seu desenvolvimento, são estudadas para recuperação de rios e lagos poluídos, efluentes provenientes de indústrias têxteis, carcinicultura e diversos outros materiais poluentes [Mauro et al., 1999; Lin et al., 2002; Dinardi et al., 2003; Henry-Silva \& Camargo, 2008].

No entanto, a utilização destas plantas em ambientes muito contaminados e sem a aplicação de um manejo adequado, pode trazer diversos prejuízos aos usos múltiplos de rios, lagos e represas, dificultando a navegação e a captação de água, prejudicando a geração de energia elétrica, comprometendo as atividades de lazer, bloqueando o fluxo de água em canais de irrigação e contribuindo para a diminuição de oxigênio dissolvido na água, podendo causar a eutrofização do corpo aquático [Velini et al., 2005; CarvaIho et al. 2005; Negrisoli et al., 2006; Henry-Silva et al., 2008].

Estudos das absorções de nitrato, por cinco espécies de macrófitas (Pharagmites australis, Commelina communis, Penniserum purpureum, Ipomoea aquática, Pistia stratiotes) em ambientes aquáticos deixaram bastante claro os bons resultados obtidos com o uso dessas plantas na retirada de poluentes, como também a necessidade de métodos alternativos como este para a resolução de problemas de contaminação devido, especialmente, ao custo necessário para se obter resultados positivos com outros métodos [Lin et al., 2002].

A estimativa mundial para os gastos com tratamento para despoluição ambiental gira em torno de 25 a 30 bilhões de dólares ao ano [Dinardi et al., 2003] com métodos convencionais. Já o tratamento de ambientes aquáticos poluídos por meio de macrófitas aquáticas apresenta baixo custo e deixa a possibilidade de reciclagem da biomassa produzida, que pode ser utilizada como ração animal, fertilizante, na geração de energia, fabricação de papel, produção de concentrado protéico para alimentação humana, artesanato, etc. [Henry-Silva et al., 2006; Verma et al., 2007; Barbieri et al., 2004; Bortolotto \& Guarim Neto, 2007].

Para se ter idéia, o teor de proteína bruta presente na espécie Eichhornia crassipes varia, em média, de 12,45\% [Henry-Silva \& Camargo, 2006] a $24,13 \%$ [Medeiros et al., 2009] nas folhas e pecíolos, variando de acordo com as características do ambiente e condições em que é cultivada.

O conhecimento desses valores torna-se ainda mais relevante considerando-se as questões sociais da região, pois o Rio Apodi/Mossoró compreende uma área em que a população sofre constantemente com a seca. Sendo assim, dependendo de sua composição, as macrófitas aquáticas poderiam ser utilizadas para a alimentação de seus animais e até mesmo para a alimentação humana.

Portanto, este trabalho teve como objetivo determinar a influência temporal na quantidade de nitrogênio total e proteína bruta em macrófitas aquáticas da espécie Eichhornia crassipes presentes no Rio Apodi/Mossoró e verificar a viabilidade do uso da biomassa produzida.

\section{Material e Métodos}

Foram realizadas colheitas a cada 2 meses em um trecho do Rio Apodi/Mossoró que corta a cidade de Mossoró (Leito principal) com início em agosto de 2008 e término em fevereiro de 2009, num total de 4 colheitas. Após as mesmas, as amostras foram armazenadas em sacos plásticos com um pouco de água dos próprios locais e levadas ao laboratório de físicoquímica da Universidade do Estado do Rio Grande do Norte - UERN, onde foram separadas em folhas (limbo + pecíolo) e raízes (Figura 1), ambas lavadas com água da torneia $\mathrm{e}$ enxaguadas exaustivamente com água destilada. 
Um espécime foi colhido aleatoriamente e levado ao laboratório de Biologia da UERN onde foi identificado como pertencente à família Pontederiaceae Kunth, espécie Eichhornia crassipes, e armazenado em local específico [Souza \& Lorenzi, 2008; Gonçalves \& Lorenzi, 2007].

Para a medida da área foliar média de uma planta $(\mathrm{AF})$, considerando área foliar como sendo apenas a área do limbo, utilizou-se o equipamento de medição de área foliar de bancada LI-COR 3100 AREA METER.

A massa foliar úmida média de uma planta (MFU) foi determinada através da pesagem em balança analítica. As folhas e raízes úmidas foram então colocadas em sacos de papel e secas em estufa com circulação forçada de ar a $60^{\circ} \mathrm{C}$ até peso constante (aproximadamente 6 dias) [EMBRAPA, 1999]. Após a desidratação, as folhas foram pesadas para a obtenção da massa foliar seca (MFS), e em seguida trituradas e acondicionadas em frascos de plástico até a realização das medidas.

Os teores de nitrogênio total (NT) foram determinados segundo o método de Kjeldahl [EMBRAPA, 1999]. Os teores de proteína bruta (PB) foram calculados multiplicando-se os valores de nitrogênio por 6,25 [Boyd, 1970].

Para o tratamento estatístico foi feito o teste de Tukey ao nível de $5 \%$ de probabilidade utilizando o programa ASSISTAT Versão 7.5 beta (2008).

\section{Resultados e Conclusões}

De acordo com os resultados obtidos (Tabela 1 e Figura 2) constatou-se que os valores de área foliar, massa foliar úmida e massa foliar seca aumentam com o tempo de crescimento das plantas mantendo-se constante na última coIheita devido, provavelmente, as mesmas terem atingido o estágio de maturidade. Vale destacar que estes parâmetros foram medidos com o objetivo de se ter um acompanhamento do tamanho da planta, e assim, verificar a influência temporal nos teores de nitrogênio total e proteína bruta.

Quanto aos valores de nitrogênio total nas folhas (limbo + pecíolo) da Eichhornia crassipes pôde-se observar o comportamento inverso, ou seja, a quantidade desse nutriente diminuiu com o tempo de crescimento da planta. O mesmo comportamento se seguiu para os níveis de proteína bruta, já que este parâmetro é diretamente proporcional aos valores de nitrogênio total (Tabela 1 e Figura 3 ). Em trabalhos realizados por
Henry-Silva \& Camargo (2006) e Medeiros et al. (2009), os mesmos encontraram resultados da mesma ordem no tecido vegetal da Eichhornia crassipes.

Tal comportamento pode ser explicado pelas alterações fisiológicas que ocorrem com o desenvolvimento das plantas onde, com a maturidade das mesmas, os níveis de nutrientes tendem a diminuir. Além disso, pode também ser decorrente da competição existente entre as macrófitas, pois, como falta espaço lateral para o seu crescimento devido ao grande número de plantas, as mesmas tendem a crescer verticalmente, fato visualmente comprovado pelo aumento do tamanho do pecíolo. Sendo assim, como o pecíolo desenvolve-se notoriamente mais que o limbo, e como o teor de proteína no primeiro é bem menor que no segundo, ocorre um efeito de diluição, ou seja, quanto maiores forem as plantas, menores serão os teores de proteína [Rosa \& Silva, 1997]. Ainda, o que também pode ter influenciado nesse comportamento, são os níveis de nitrogênio presentes na água, já que os nutrientes absorvidos pelas macrófitas são provenientes do meio em que as mesmas estavam inseridas. Aspectos estes que estão sendo investigados e serão objetos de publicações posteriores.

Para as raízes, o mesmo comportamento foi observado. A única exceção ocorreu para o mês de dezembro de 2008 ( $3^{a}$ colheita), onde há um pequeno aumento da quantidade de nitrogênio total quando comparada com a colheita anterior. Isto se deve ao aumento da concentração deste nutriente na própria água, causado pela diminuição do volume desta. Como o mês de dezembro é o período mais seco da região, esta deve, provavelmente, ser a causa desse comportamento adverso.

Comparando os valores de nitrogênio total e proteína bruta presentes nas folhas com os valores encontrados nas raízes, pôde-se constatar que estas apresentaram níveis bem menores que as folhas. Tal comportamento ocorreu pelo fato do nitrogênio ser essencial para o desenvolvimento da planta. Sendo assim, o transporte deste nutriente das raízes para as folhas é facilitado, fazendo com que estas apresentem maiores concentrações de nitrogênio e, consequentemente, de proteína bruta [Alves et al., 2003].

Pode-se ainda utilizar estes dados para fazer um comparativo do teor de proteína bruta presente nessa espécie de macrófita aquática com a quantidade presente em alguns alimentos, 
podendo-se assim, propor uma forma de aproveitamento da biomassa produzida em relação a variável analisada.

Comparando-se os valores de proteína bruta presente nas amostras de Eichhornia crassipes colhidas no Rio Apodi/Mossoró com a quantidade de proteína bruta presente em alguns alimentos destinados ao consumo humano, de acordo com a Tabela brasileira de composição de alimentos (TACO) pode-se observar que a planta em questão apresenta níveis muito maiores ou próximos aos alimentos considerados ricos em proteína. Segundo a TACO, os valores encontrados em alguns alimentos vegetais são: para arroz integral cru $(7,3 \mathrm{~g} / 100 \mathrm{~g})$, farinha de trigo $(9,8 \mathrm{~g} / 100 \mathrm{~g})$, alface crespa crua $(1,3 \mathrm{~g} / 100$ g), e feijão broto cru $(4,2 \mathrm{~g} / 100 \mathrm{~g})$, por exemplo.

Portanto, tomando como base apenas os valores de proteína presentes na macrófita aquática, conclui-se que:

1) Os parâmetros analisados são bastante influenciados pela variabilidade temporal;

2) As macrófitas aquáticas da espécie Eichhornia crassipes presentes no Rio Apodi/Mossoró poderiam ser utilizadas para diversos fins, como por exemplo, na alimentação animal, ou mesmo, na obtenção de um concentrado protéico destinado a alimentação humana.

A grande disponibilidade de biomassa aliada a sua alta velocidade de crescimento e o pequeno período de cultivo necessário para se obter o máximo de proteína, tornaria esta uma alternativa viável de aproveitamento da biomassa produzida. No entanto, para que isto seja possível é necessário estudar os teores de outros nutrientes e elementos tóxicos no tecido vegetal.

Desta forma, a constatação do alto teor de proteína nas macrófitas pequenas é de grande importância, tendo em vista a necessidade da população em fazer uso, principalmente, na alimentação de animais que em período de seca acabam morrendo por falta de alimentação adequada. Além disso, vale ressaltar que a mesma não teria custo com a produção, já que as plantas nascem e crescem o ano todo, naturalmente, em vários pontos do rio.

\section{Referências}

1. ALVES, E.; CARDOSO, L. R.; SCRAVONI, J.; FERREIRA, L. C.; BOARO, C. S. F.; CATANEO, A. C.
Avaliações fisiológicas e bioquímicas de plantas de aguapé (Eichhornia crassipes) cultivadas com níveis excessivos de nutrientes. Planta Daninha, v. 21, p. 2735, 2003. Ed. Especial.

2. BARBIERI, R.; CARIDADE, E. O.; ALMEIDA, I. C. S.; BEZERRA, D. S.; DINIZ, S. C. C. S. Conteúdo de proteína, cinzas e sais minerais de plantas herbáceas utilizadas como forrageiras em tanques de piscicultura (Vitória do Mearim, MA). Boletim do Laboratório de Hidrobiologia, v. 17, p. $43-47,2004$.

3. BORTOLOTTO, I. M.; GUARIM NETO, G. Uso do camalote, Eichhornia crassipes (mart.) Solms, Pontederiaceae, para confecção de artesanato no Distrito de Albuquerque, Corumbá, MS, Brasil. Acta Bot. Bras, v.39, n. 2, abr./jun, 2005.

4. BOYD, C. E. Aminoacids protein and caloric content of aquatic macrophytes, Ecology 51 (1970) 902 906.

5. CARVALHO, F. T.; VELINI, E. D.; NEGRISOLI, E.; ROSSI, C. V. S. Eficácia do Carfentrazone-Ethyl no controle de plantas aquáticas latifoliadas em caixas d'água. Planta Daninha, v. 32 , n. 2, p. $305-310,2005$.

6. DINARDI, A. L.; FORMAGI, V. M.; CONEGLIAN, C. M. R.; BRITO, N. N.; DRAGONI SOBRINHO, G.; TONSO, S.; PELEGRINI, R. Fitorremediação. In: Fórum de Estudos Contábeis, 3, 2003. Rio Claro - SP. Anais...Rio Claro: Faculdades Interligadas Claretianas, 2003.

7. EMBRAPA - Empresa Brasileira de Pesquisa Agropecuária. Manual de análises químicas de solos, plantas e fertilizantes. Brasília: Embrapa, 1999.

8. GONÇALVES, C. V. Alometria foliar, biomassa e fitoacumulação de cromo em Eichhornia crassipes (Mart.) Solms. 2006. 76f. Dissertação (Mestrado em Ecologia) - Instituto de Biociência, Universidade Federal do Rio Grande do Sul, Porto Alegre - RS.

9. GONÇALVES, E. G. \& LORENZI, H. Morfologia vegetal: organografia e dicionário ilustrado de morfologia das plantas vasculares. São Paulo: Instituto Plantarum de estudos da Flora, 2007.

10. HENRY-SILVA, G. G.; CAMARGO, A. F. M. Composição química de macrófitas 
aquáticas flutuantes utilizadas no tratamento de efluentes de aqüicultura. Planta Daninha, v. 24, n. 1 , p. 21-28, 2006.

11. HENRY-SILVA, G. G.; CAMARGO, A. F. M. Tratamento de efluentes da carcinicultura por macrófitas aquáticas flutuantes. Revista Brasileira de Zootecnia, v. 37 , n. 2, p. $181-188$, 2008.

12. HENRY-SILVA, G. G.; CAMARGO, A. F. M.; PEZZATO, L. E. Digestibilidade aparente de macrófitas aquáticas pela tilápia-do-nilo (Oreochromis niloticus) e qualidade da água em relação às concentrações de nutrientes. Revista Brasileira de Zootecnia, v. 35, n. 3, p. 1 $-7,2006$.

13. HENRY-SILVA, G. G.; CAMARGO, A. F. M.; PEZZATO, L. E. Growth of freefloating aquatic macrophytes in different concentrations of nutrients. Hydrobiologia, v. 610 , n. 1, p. $153-160$, 2008.

14. LIN, Y.; JING, S.; WANG, T.; LEE, D. Effects of macrophytes and external carbon sources on nitrate removal from groundwater in constructed wetlands. Environmental Pollution, v. 119, n. 3, p. 413 - 420, Out 2002.

15. MARTINS, D. F. F.; SOUZA, L. D.; CASTRO, S. S. L. Qualidade físicoquímica das águas da bacia do Rio Apodi/Mossoró: II - Variabilidade temporal. Química no Brasil, v. 2, n. 2, p. 9 - 23, 2008.

16. MARTINS, D. F. F.; SOUZA, R. B.; OLIVEIRA, T. M. B. F.; SOUZA, L. D.; CASTRO, S. S. L. Qualidade físicoquímica das águas da bacia do Rio Apodi/Mossoró: I - Variabilidade espacial. Química no Brasil, v. 2, n. 1, p. $61-74$, 2008.

17. MAURO, J. B. N.; GUIMARÃES, J. R. D.; MELAMED, R. Aguapé agrava contaminação por mercúrio. Ciência Hoje, v. 25, n. 150, p. 68 - 71, 1999.

18. MEDEIROS, R. M. L.; SRUR, A. U. O. S;
PINTO, C. L. R. Estudo da biomassa de aguapé, para a produção do seu concentrado protéico. Ciência e Tecnologia de Alimentos, v. 19, n. 2, Maio/Ago 1999.

19. NEGRISOLI, E.; CORRÊA, M. R.; VELINI, E. D.; BRAVIN, L. F.; MARCHI, S. R.; CAVENAGHI, A. L.; ROSSI, C. V. S. Estudo da degradação da biomassa de três espécies de plantas aquáticas no reservatório da UHE de Americana-SP. Planta Daninha, v. 24 , n. 2, p. $221-227$, 2006.

20. ROSA, B.; SILVA, S. R. C. Produção e características químicas do capimelefante (Pennisetum purpureum Shum) para ensilagem em diferentes idades de corte. Anais da Esc. Agron. e Vet., v. 27, n. 2, p. $99-107,1997$.

21. SOUZA, V. C. \& LORENZI, H. Botânica Sistemática: Guia ilustrado para identificação das famílias de Angiospermas da flora brasileira, baseado em APG II. $2^{\circ}$ ed. Nova Odessa, SP: Instituto Plantarum, 2008.

22. Tabela brasileira de composição de alimentos / NEPA-UNICAMP. Versão II. $2^{\mathrm{a}}$ ed., Campinas, SP: NEPA-UNICAMP, 2006. 113p.

23. VELINI, E. D.; CORRÊA, M. R.; NEGRISOLI, E.; BRAVIN, L. F. N.; CAVENAGHI, A. L.; ROSSI, C. V. S.; SILVA, J. R. M. Estudo da decomposição de plantas aquáticas em função das quantidades depositadas, da umidade e do tipo de disposição no solo. Planta Daninha, v. 23, n. 2, p. $249-254,2005$.

24. VERMA, V. K.; SINGH, Y. P.; RAI, J. P. $\mathrm{N}$. Biogas production from plant biomass used for phytoremediation of industrial wastes. Bioresource Technology, v. 98, p. 1664 - 1669, 2007. 


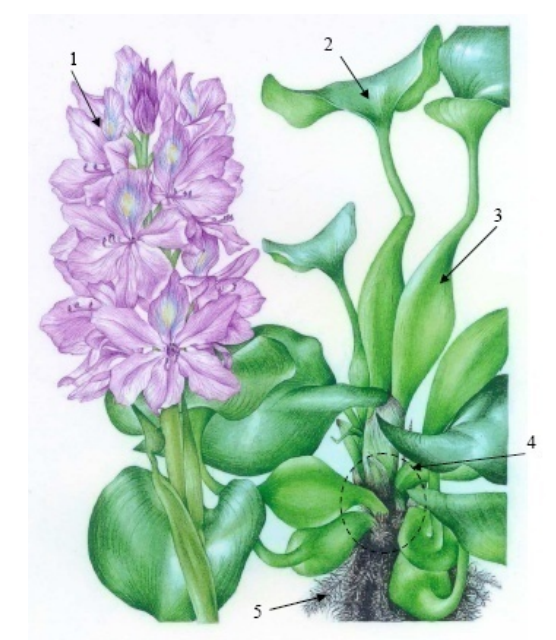

Figura 1 - Divisão estrutural da Eichhornia crassipes. 1 - Flor. 2 - Limbo. 3 - Pecíolo. 4 - Rizoma. 5 - Raiz. Fonte: Gonçalves, 2006.

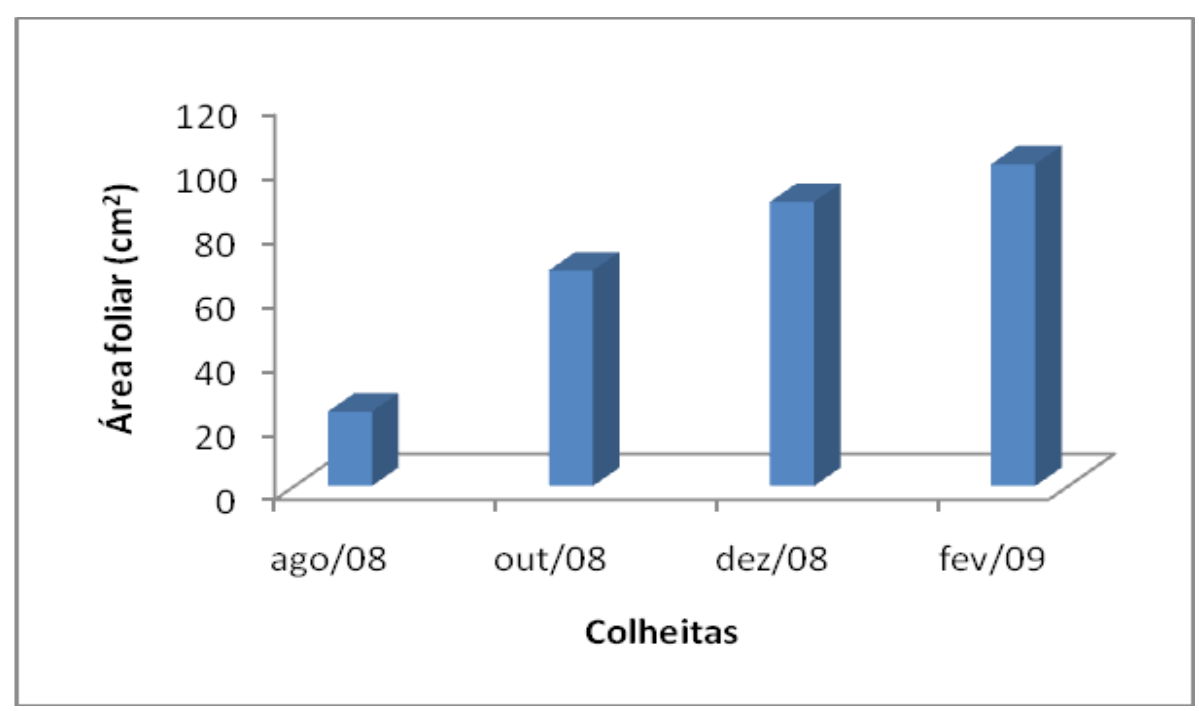

Figura 2 - Valores de área foliar em função do tempo de crescimento das plantas. 


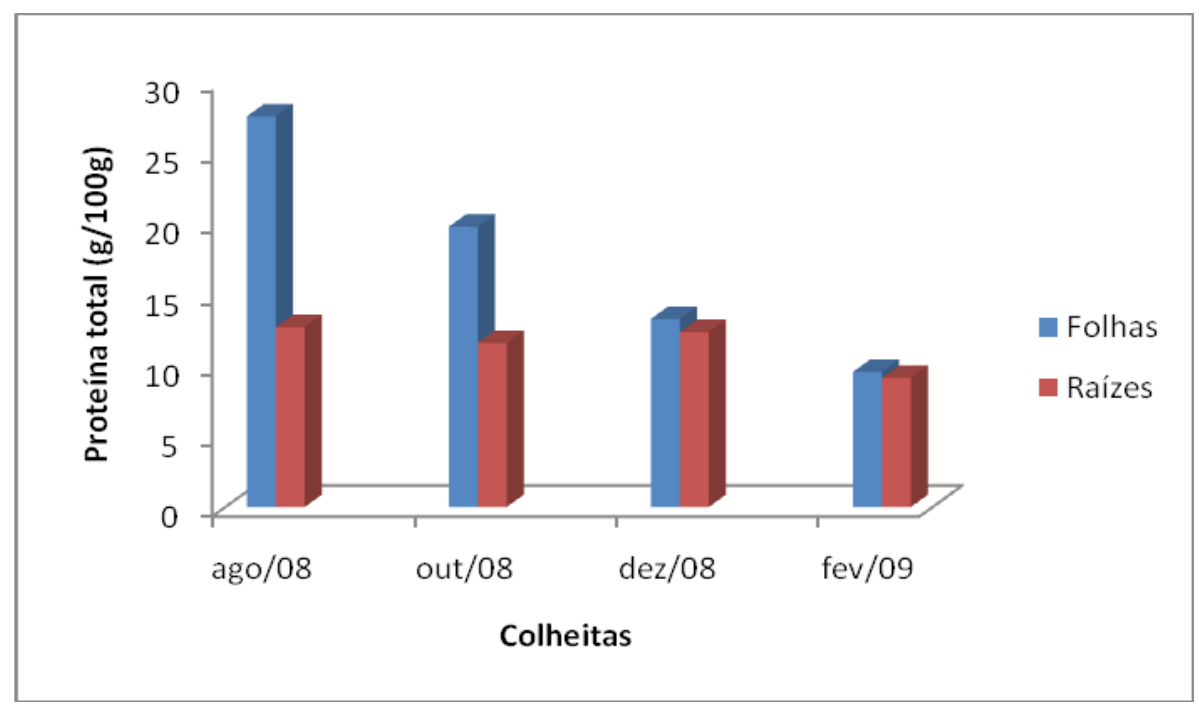

Figura 3 - Teores de proteína bruta nas folhas e raízes em função do tempo de crescimento das plantas.

Tabela 1: Médias e desvios padrões das medidas.

\begin{tabular}{|c|c|c|c|c|}
\hline \multirow{2}{*}{$\begin{array}{c}\text { Local } \\
\text { Período }\end{array}$} & \multicolumn{4}{|c|}{ Leito principal } \\
\hline & $\begin{array}{l}\text { Agosto/08 } \\
\text { (0 mês) }\end{array}$ & $\begin{array}{l}\text { Outubro/08 } \\
\text { (2 meses) }\end{array}$ & $\begin{array}{c}\text { Dezembro/08 } \\
\text { (4 meses) }\end{array}$ & $\begin{array}{c}\text { Fevereiro/09 } \\
\text { (6 meses) }\end{array}$ \\
\hline $\mathrm{AF}\left(\mathrm{cm}^{2}\right)$ & $23,17 \pm 2,79(a)$ & $67,21 \pm 6,01$ (b) & $88,59 \pm 9,87$ (c) & $100,29 \pm 14,00$ (c) \\
\hline MFU (g) & $0,6578 \pm 0,1030(a)$ & $1,9984 \pm 0,2000(b)$ & $2,6484 \pm 0,4601$ (c) & $3,0906 \pm 0,6151$ (c) \\
\hline MFS (g) & $0,0913 \pm 0,0187(a)$ & $0,2745 \pm 0,0221(b)$ & $0,4448 \pm 0,0667$ (c) & $0,5034 \pm 0,1099$ (c) \\
\hline $\begin{array}{l}\text { NT (folha) } \\
\text { (g/100g) }\end{array}$ & $4,4088 \pm 0,0747$ (a) & $3,1649 \pm 0,0117(b)$ & $2,1241 \pm 0,0348 \quad(\mathrm{c})$ & $1,5256 \pm 0,0177(d)$ \\
\hline $\begin{array}{l}\text { PB (folha) } \\
\text { (g/100g) }\end{array}$ & $27,5549 \pm 0,4666(a)$ & $19,7805 \pm 0,0730(b)$ & $13,2755 \pm 0,2176$ (c) & $9,5351 \pm 0,1106(d)$ \\
\hline $\begin{array}{l}\text { NT (raiz) } \\
\text { (g/100g) }\end{array}$ & $2,0306 \pm 0,0124(a)$ & $1,8522 \pm 0,0153$ (b) & $1,9761 \pm 0,0372(a)$ & $1,4595 \pm 0,0238(\mathrm{c})$ \\
\hline $\begin{array}{l}\text { PB (raiz) } \\
(\mathrm{g} / 100 \mathrm{~g})\end{array}$ & $12,6911 \pm 0,0777(a)$ & $11,5761 \pm 0,0953(b)$ & $12,3507 \pm 0,2328(a)$ & $9,1218 \pm 0,1488$ (c) \\
\hline
\end{tabular}

As médias seguidas pela mesma letra nas linhas não diferem estatisticamente entre si. Foi aplicado o Teste de Tukey ao nível de $5 \%$ de probabilidade. 